Marquette University

e-Publications@Marquette

Biomedical Engineering Faculty Research and

Publications

Biomedical Engineering, Department of

$5-2011$

\title{
A Rapid and Computationally Inexpensive Method to Virtually Implant Current and Next-Generation Stents into Subject-Specific Computational Fluid Dynamics Models
}

\author{
Timothy J. Gundert \\ Marquette University \\ Shawn C. Shadden \\ Illinois Institute of Technology \\ Andrew R. Williams \\ Marquette University \\ Bon-Kwon Koo \\ Seoul National University College of Medicine \\ Jeffrey A. Feinstein \\ Stanford University
}

See next page for additional authors

Follow this and additional works at: https://epublications.marquette.edu/bioengin_fac

Part of the Biomedical Engineering and Bioengineering Commons

\section{Recommended Citation}

Gundert, Timothy J.; Shadden, Shawn C.; Williams, Andrew R.; Koo, Bon-Kwon; Feinstein, Jeffrey A.; and LaDisa, John F., "A Rapid and Computationally Inexpensive Method to Virtually Implant Current and NextGeneration Stents into Subject-Specific Computational Fluid Dynamics Models" (2011). Biomedical Engineering Faculty Research and Publications. 2.

https://epublications.marquette.edu/bioengin_fac/2 
Authors

Timothy J. Gundert, Shawn C. Shadden, Andrew R. Williams, Bon-Kwon Koo, Jeffrey A. Feinstein, and John F. LaDisa 


\title{
A Rapid and Computationally Inexpensive Method to Virtually Implant Current and Next- Generation Stents into Subject- Specific Computational Fluid Dynamics Models
}

\author{
Timothy J. Gundert \\ Department of Biomedical Engineering, Marquette University, \\ Milwaukee, WI \\ Shawn C. Shadden \\ Mechanical, Materials and Aerospace Engineering, Illinois \\ Institute of Technology \\ Chicago, $I L$, \\ Andrew R. Williams \\ Department of Biomedical Engineering, Marquette University, \\ Milwaukee, WI \\ Bon-Kwon Koo \\ Seoul National University College of Medicine \\ Seoul, Korea
}




\author{
Jeffrey A. Feinstein \\ Department of Pediatrics (Cardiology) \\ Department of Bioengineering \\ Lucile Packard Children's Hospital and Stanford University School \\ of Medicine, \\ Palo Alto, $C A$ \\ John F. LaDisa, Jr. \\ Department of Biomedical Engineering, Marquette University \\ Department of Medicine, Division of Cardiovascular Medicine, \\ Medical College of Wisconsin \\ Department of Pediatrics, Division of Pediatrics, Children's \\ Hospital and the Medical College of Wisconsin \\ Milwaukee, WI
}

\begin{abstract}
Computational modeling is often used to quantify hemodynamic alterations induced by stenting, but frequently uses simplified device or vascular representations. Based on a series of Boolean operations, we developed an efficient and robust method for assessing the influence of current and next-generation stents on local hemodynamics and vascular biomechanics quantified by computational fluid dynamics. Stent designs were parameterized to allow easy control over design features including the number, width and circumferential or longitudinal spacing of struts, as well as the implantation diameter and overall length. The approach allowed stents to be automatically regenerated for rapid analysis of the contribution of design features to resulting hemodynamic alterations. The applicability of the method was demonstrated with patient-specific models of a stented coronary artery bifurcation and basilar trunk aneurysm constructed from medical imaging data. In the coronary bifurcation, we analyzed the hemodynamic difference between closed-cell and open-cell stent geometries. We investigated the impact of decreased strut size in stents with a constant porosity for increasing flow stasis within the stented basilar aneurysm model. These examples demonstrate the current method can be used to investigate differences in stent performance in complex vascular beds for a variety of stenting procedures and clinical scenarios.
\end{abstract}

Annals of Biomedical Engineering, Vol. 39, No. 5 (May 2011): pg. 1423-1437. DOI. This article is (C) Springer and permission has been granted for this version to appear in e-Publications@Marquette. Springer does not grant permission for this article to be further copied/distributed or hosted elsewhere without the express permission from Springer. 
NOT THE PUBLISHED VERSION; this is the author's final, peer-reviewed manuscript. The published version may be accessed by following the link in the citation at the bottom of the page.

\section{Introduction}

Hemodynamic forces including pressure, strain, and indices of wall shear stress (WSS) influence the onset and progression of cardiovascular disease (CVD) and the efficacy of devices used for its treatment. For example, stent-induced changes in vascular biomechanics can lead to lumen stiffening, local compliance mismatch and vascular or stent damage. ${ }^{5,16}$ In addition to the chronic radial force introduced on the vessel by a stent and the corresponding loading imparted on the stent by a vessel, associated changes in local vascular geometry and subsequent indices of WSS have been shown to influence sequelae such as neointimal hyperplasia, restenosis, and potential for thrombus formation in the coronary arteries. ${ }^{24}$ When coupled with the NIH Roadmap for Medical Research and the FDA's Critical Path to New Medical Products, which both advocate the development and application of advanced scientific resources for evaluating medical products and data, these findings indicate there is a need for a rapid and robust method of evaluating current and emerging stent designs based in their impact on hemodynamics and vascular biomechanics.

Computational fluid dynamics (CFD) offers a noninvasive tool to quantify hemodynamic indices in vessels reconstructed from imaging data and to relate spatiotemporal patterns of these indices to vascular disease. 47,52 While previous CFD studies conducted to date in response to stenting have been invaluable, creating a detailed stent geometry from imaging data has only been accomplished using polytetrafluoroethylene tubes and ex vivo arterial segments. ${ }^{4}$ In contrast, idealized computational models of deployed stents have often used simplified device or vascular representations. ${ }^{21,22}$ Solid mechanics studies of stent expansion with subsequent flow analysis undoubtedly offer an ideal approach for scrutinizing devices, but involve several potential limitations. For example, these studies are typically performed with only a portion of the stent, representing a few millimeters in length, but the typical length of stents implanted in the superficial femoral arteries can exceed $100 \mathrm{~mm}$ in length. Patientspecific modeling of stent-induced hemodynamics and vascular biomechanics also first requires modeling stent implantation using

Annals of Biomedical Engineering, Vol. 39, No. 5 (May 2011): pg. 1423-1437. DOI. This article is C Springer and permission has been granted for this version to appear in e-Publications@Marquette. Springer does not grant permission for this article to be further copied/distributed or hosted elsewhere without the express permission from Springer 
solid mechanics, which is computationally expensive. As a result, a full-scale analysis of this type is rare.

The objective of this investigation was to develop a rapid and robust method for assessing the influence of current and nextgeneration stents on patient-specific local hemodynamics and vascular biomechanics quantified by CFD. As opposed to a full-scale approach of solid mechanics modeling with subsequent CFD, we determine the post-implantation deformation of strut linkages for a portion of the investigated stent using finite element analysis (FEA) or microscopy if the expanded orientation of linkages is not previously known, and then use computer aided design (CAD) to propagate the knowledge of strut deformation throughout the full length of a stent for virtual implantation into patient-specific CFD models. The organization of this investigation begins with a description of the methods imposed to virtually implant commercially available, next-generation or prototype stents within a CFD model. The use of this new method is then applied in two examples using patient-specific CFD models generated from the coronary and cerebral portions of the arterial vasculature. Importantly, each of these examples highlights the use of these methods to investigate current clinical sequelae and potential sources of long-term morbidity thought to be influenced by adverse hemodynamic alterations.

\section{Methods}

\section{Patient-Specific CFD Model Creation}

Computational representations of the vasculature were created using Simvascular open source software (https://simtk.org/home/simvascular), which facilitates volume visualization and conversion of medical imaging data into geometrically representative computer models (Figs. 1a1 to 1a3). The process involves finding the centerline path of each artery, performing segmentation to delineate the arterial wall and connecting these segments to form a Parasolid model (Siemens, Plano, TX). In cases where the stent-toartery deployment ratio used clinically would alter the global geometry within the stented region (i.e., for balloonexpandable stents) physician guidance is required to alter segments

Annals of Biomedical Engineering, Vol. 39, No. 5 (May 2011): pg. 1423-1437. DOI. This article is (C) Springer and permission has been granted for this version to appear in e-Publications@Marquette. Springer does not grant permission for this article to be further copied/distributed or hosted elsewhere without the express permission from Springer. 
NOT THE PUBLISHED VERSION; this is the author's final, peer-reviewed manuscript. The published version may be accessed by following the link in the citation at the bottom of the page.

within the stented region of the vessel according to standard interventional procedures. ${ }^{44,53}$

\section{Creation of Stents}

The current approach requires knowledge of the expanded orientation of strut linkages. If not known, this information can be determined in a number of ways including performing FEA for a portion of the stent ${ }^{35,36}$ or deploying a stent and quantifying the orientation of its strut linkages using light microscopy or microfocal X-ray CT. ${ }^{34,41} \mathrm{~A}$ CAD drawing of the expanded stent pattern is then created. The drawing is constrained using a set of equations and other criteria that allow the user to easily control specific features of the model. This parametric approach allows for properties including the number, width, and circumferential or longitudinal spacing (i.e., scaffolding) of struts, as well as the implantation diameter and stent length, to be easily adapted using variables. The drawing can then automatically be regenerated for rapid parametric analysis of the contribution of these parameters to resulting hemodynamic alterations since it dictates the geometry of the stent model as described by the following procedure.

The drawing of the expanded stent is wrapped around a tube with a diameter slightly larger than the vessel in which the stent will be virtually implanted and a thickness $>5$ times the desired stent thickness. The cell geometry of the stent is then cutout of the tube, resulting in a stent design that accurately represents a commercial available stent with an accentuated radial thickness. Each stent design in this study was created using CAD software capable of saving a Parasolid document such as Solidworks (Solidworks Corp., Concord, MA) or SolidEdge (Siemens, Plano, TX) in order to facilitate integration of the vessel and stent models.

\section{Virtual Stent Implantation}

Virtual stent implantation is achieved using a series of Boolean operations. The thick stent is flexed to match the curvature of the vessel (Fig. 1b4). A separate solid model of the vessel to undergo virtual stenting in the absence of any branches is created and hollowed to the desired stent thickness (Fig. 1c1). A Boolean intersection

Annals of Biomedical Engineering, Vol. 39, No. 5 (May 2011): pg. 1423-1437. DOI. This article is (C) Springer and permission has been granted for this version to appear in e-Publications@Marquette. Springer does not grant permission for this article to be further copied/distributed or hosted elsewhere without the express permission from Springer. 
operation is then performed with the hollowed vessel and thick stent to yield a computational representation of the stent to undergo virtual implantation (Figs. 1c2 to 1c3). A Boolean subtraction operation is then performed with this stent and the patient-specific model in order to remove the stent from the lumen and generate the flow domain for analysis (Fig. 1C4). In the presence of branching arteries, the Boolean intersection that yields the patient-specific stent is performed only on the main vessel. The subsequent subtraction of the patient-specific stent is performed on the entire model of the vasculature such that the struts of the stent partially occlude the branching arteries.

\section{Specification of Boundary Conditions and Simulation Parameters}

Boundary conditions varied slightly between applications and specific details unique to each vascular bed will be presented in the subsequent examples. Generally, inlet boundary conditions were obtained from experimental data ${ }^{10,19}$ and outlet boundary conditions that replicate measured blood flow and pressure were applied. To replicate the physiologic influence of vessels distal to CFD model branches, a three-element Windkessel representation was imposed at model outlets using a coupled-multidomain method. ${ }^{55}$ Importantly, this approach can only be applied to the coronary arteries by neglecting the contribution of ventricular contraction. ${ }^{54}$ Nonetheless, the threeelement Windkessel method provides a good estimate of the arterial tree beyond model outlets ${ }^{59}$ and can be described by three main parameters with physiologic meaning: $R_{\mathrm{c}}, \mathrm{C}$, and $R_{\mathrm{d}} . R_{\mathrm{C}}$ is the characteristic impedance representing the resistance, compliance, and inertance of the proximal artery of interest, $C$ is the arterial capacitance and represents the collective compliance of all arteries beyond a model outlet, and $R_{\mathrm{d}}$ describes the total distal resistance beyond a given outlet. The terminal resistance $\left(R_{\mathrm{t}}\right)$ for each model outlet was determined from mean blood pressure (BP) and flow measurements and distributed between $R_{\mathrm{c}}$ and $R_{\mathrm{d}}$ as described below. The total arterial compliance (TAC) for each patient was determined using the measured inflow and BP measurements and assuming a $R_{\mathrm{c}}$ : $\mathrm{R}_{\mathrm{t}}$ ratio of $6 \% .{ }^{26}$ The TAC was then distributed among outlets according to their blood flow distributions ${ }^{48}$ and $R_{\mathrm{c}}$ : $\mathrm{R}_{\mathrm{t}}$ ratios for each

Annals of Biomedical Engineering, Vol. 39, No. 5 (May 2011): pg. 1423-1437. DOI. This article is (C) Springer and permission has been granted for this version to appear in e-Publications@Marquette. Springer does not grant permission for this article to be further copied/distributed or hosted elsewhere without the express permission from Springer. 
outlet were adjusted using the pulse pressure method 38,49 thereby replicating desired $\mathrm{BP}$ values.

Blood was assumed to behave as a Newtonian fluid with a density of $1.06 \mathrm{~g} / \mathrm{cm}^{3}$ and dynamic viscosity of $4 \mathrm{cP}$. Three to four cardiac cycles were run to ensure simulation results were converged with a maximum error between equivalent time points in successive cardiac cycles $<1 \mathrm{mmHg}$ and $1 \mathrm{~mm}^{3} / \mathrm{s}$ for pressure and flow, respectively. Simulations were also scrutinized to ensure results were independent of the number of mesh elements in each model. Anisotropic meshes were created with unstructured tetrahedral elements using a commercially available, automatic mesh generation program (MeshSim, Simmetrix, Clifton Park, NY). Initial meshes were generated such that the density of elements around the stent struts was much greater than throughout the rest of the model. Meshes were adapted after each pulsatile simulation to place more elements near struts and other regions where they are most needed within the flow domain while inserting fewer elements where a coarse density is sufficient. The desired mesh independence criteria strived for a change in time-averaged WSS values $<0.09 \mathrm{dyn} / \mathrm{cm}^{2}$ at predetermined proximal and distal intrastrut regions between successive meshes. ${ }^{20,37}$ Simulations were performed using a stabilized finite element method to solve equations for conservation of mass (continuity) and balance of fluid momentum (Navier-Stokes). Vessel wall elastodynamics equations were also solved where applicable. ${ }^{7}$

\section{General Quantification of Results}

After verifying that simulation results were mesh independent and replicated aimed BP and flow distributions, time-averaged wall shear stress (TAWSS) and oscillatory shear index (OSI) were calculated as previously described. ${ }^{51}$ OSI is a measure of the directionality of WSS in which lower OSI values indicate WSS is oriented predominately in the primary direction of blood flow while a value of 0.5 is indicative of bi-directional WSS with a time-average value of zero throughout the cardiac cycle. ParaView was used to visualize pressure, velocity, WSS, and OSI.

Annals of Biomedical Engineering, Vol. 39, No. 5 (May 2011): pg. 1423-1437. DOI. This article is (C) Springer and permission has been granted for this version to appear in e-Publications@Marquette. Springer does not grant permission for this article to be further copied/distributed or hosted elsewhere without the express permission from Springer. 
Flow stasis was quantified by computing mean exposure time (MET), recently defined by Lonyai et al. ${ }^{30}$ Using a particle tracking scheme, MET measures the duration particles reside within in each element of an MET mesh. In the stented models of this investigation, the mesh adaption process created highly anisotropic meshes with more elements along the stent struts, which was not suitable for computing MET. Auxiliary isotropic meshes were therefore used as part of a post-processing step for the MET calculations since this index depends on element size. To calculate MET for an element e, we define $N_{\mathrm{e}}$ as the number of times a particle passes through the element, $V_{\mathrm{e}}$ as the volume of the element, $N_{\mathrm{t}}$ as the total number of particles released, and $\mathrm{H}_{\mathrm{e}} \mathrm{e}(t)$ as equal to 1 when a particle $p$ is located inside the element at time $t$ and is equal to 0 otherwise such that the MET is given by:

$$
\operatorname{MET}_{\mathrm{e}}=\frac{1}{N_{\mathrm{e}} V_{\mathrm{e}}^{1 / 3}} \sum_{p=1}^{N_{\mathrm{t}}} \int_{0}^{\infty} H_{\mathrm{e}}^{p}(t) d t
$$

MET distinguishes between recirculating particles and stagnant particles because the duration a particle resides within an element is normalized by the $N_{\mathrm{e}}$, unlike other flow stasis measurements that quantify a cumulative duration. Lonyai et al., also normalized MET to $V_{\mathrm{e}}$, but in this investigation, MET was normalized to $V_{\mathrm{e}}{ }^{1 / 3}$. When MET is normalized to $V_{\mathrm{e}}$, small variations in element size can result in large variations in MET. Given the relatively small element size of the auxiliary meshes used in this investigation, it could be assumed particle movement through the elements was highly one-dimensional, and normalizing MET relative to $V_{\mathrm{e}}{ }^{1 / 3}$ reduced variations in MET due to slight differences in element volume.

The computational domain was seeded with a high density of particles at the start of each MET analysis. The initial seeding was supplemented with a uniform concentration of particles released from the inlet(s) of the model over the course of one cardiac cycle by matching the release rate with the local flow rate and profile. The particles were advected for numerous cycles until all the particles exited the domain. 


\section{Example 1: Comparing Hemodynamic Alterations between Stents after Virtual Coronary}

\section{Artery Implantation}

Restenosis after bare-metal stent implantation limits their success and has cost the U.S. healthcare system an estimated 2.5 billion dollars since $1999 .{ }^{45}$ Drug-eluting stents designed to combat restenosis are prone to late thrombosis that may increase the likelihood of myocardial infarction. ${ }^{9,15}$ Interestingly, these problems with bare-metal and drug-eluting stents can be explained on the basis of altered blood flow within the stented region ${ }^{11,24,43}$ suggesting that stents which optimize local hemodynamics after implantation may intrinsically reduce restenosis and the potential for thrombus formation and dislodgement. The methods described herein are therefore applied for this purpose using two different stent designs.

A CFD model was created as described above from a CT scan obtained from the OsiriX medical imaging repository (http://pubimage.hcuge.ch:8080/). The patient did not have a significant stenosis and the left anterior descending (LAD) and first diagonal branch diameters, branch angle, and radius of curvature matched published normal values. ${ }^{8,40}$ Computational representations of an open-cell ring-and-link design (Stent A) and a close-cell slotted tube prototype design (Stent $B$ ) created through contract manufacturing for use with experimental investigations in our laboratory were virtually implanted using the methods described above (Figs. 2ato $2 b$ ). The resulting stented vessels mimicked the clinical practice of main vessel stenting without subsequent side branch balloon angioplasty. An LAD blood flow waveform at rest ${ }^{20}$ was applied at the model inlet and outlet boundary conditions that replicated flow and pressure in the absence of ventricular contraction were applied using Simvascular. ${ }^{54}$ A stent-to-artery deployment ratio of $1: 1$ was assumed. The stent was modeled as rigid while the modulus of elasticity and thickness of the vessel wall were selected to match the deformation previously observed in response to the imposed resting flow conditions. ${ }^{39}$ 
Previous studies have demonstrated that distributions of TAWSS $<4 \mathrm{dyn} / \mathrm{cm}^{2}$ and high temporal oscillations in WSS quantified by OSI are associated with cellular proliferation, intimal thickening, and inflammation. ${ }^{12}$ An automated computer program was used to quantify the area of the stented region containing TAWSS $<4 \mathrm{dyn} / \mathrm{cm}^{2}$ and the area of the lumen surface containing OSI $>0.1$. Due to differences in intrastrut area (i.e., scaffolding) and the number of strut linkages between the similarly sized stents, TAWSS and OSI were normalized to the overall area of the stent interfacing with the luminal wall. Intrastrut wall strain was quantified by measuring the change in the circumference of the vessel wall between systole and diastole at the point of the largest wall displacement. MET was computed at the bifurcation to visualize flow stasis in both the main and side branches induced by stent placement.

To visualize TAWSS and displacement over the entire stented region, the surface geometry of vessels was unwrapped whereby each $(x, y, z)$ node of the surface mesh representing the vessel was mapped to a $(h, l)$ coordinate system. The dimension $\theta$ represents the circumferential location of the node for $0^{\circ}-360^{\circ}$ in which the zero degree location was arbitrarily chosen. The dimension / represents the length along the vessel in which the node was located. All lengths were measured relative to a piecewise cubic spline which defined the centerline of the vessel.

\section{Example 2: Quantifying the Effect of Stent Strut Size on Cerebral Aneurysm}

\section{Hemodynamics}

Cerebral aneurysm rupture is the second leading cause of stroke in the United States. ${ }^{29}$ To avoid rupture, blood flow to an aneurysm can be occluded to promote flow stagnation and induce thrombosis by means of surgical clipping or endovascular devices including coils and stents. In saccular aneurysms, coiling has been shown to be an effective treatment for rupture prevention. ${ }^{33}$ Wide-necked aneurysms are more difficult to treat, and often a stent is used in conjunction with coiling to facilitate thrombosis in these cases. ${ }^{46,57}$ Stent porosity, strut size, and cell geometry have all been identified as factors that affect

Annals of Biomedical Engineering, Vol. 39, No. 5 (May 2011): pg. 1423-1437. DOI. This article is @ Springer and permission has been granted for this version to appear in e-Publications@Marquette. Springer does not grant permission for this article to be further copied/distributed or hosted elsewhere without the express permission from Springer. 
cerebral stent performance. ${ }^{3,18}$ Decreased strut size of helical stents has been shown to favorably alter flow in idealized aneurysms geometries using particle image velocimetry (PIV). ${ }^{28}$ The objective of this example was to evaluate how the strut size of a stent design similar to the commercially available Neuroform2 (Boston Scientific Neurovascular, Fremont, CA) stent affects hemodynamics in a patientspecific model of a wide-necked aneurysm using the computational stenting methods described above.

A cerebral model of a patient with a large basilar trunk aneurysm was constructed from MRI imaging data also obtained from the OsiriX medical imaging repository. Three stent designs similar to the Neuroform 2 were modeled in an expanded configuration using the parametric modeling techniques described earlier. All stents had the same porosity but their strut size was varied for use in three CFD models. The number of longitudinal and circumferential repetitions was increased as stent strut size decreased in order to maintain a constant porosity in each model as shown by the design specifications in Table 1. Though these stents are often used in conjunction with coils, only a stent model was placed across the neck of the aneurysm in order to isolate and characterize stent performance. Both the stent and vasculature were assumed to be rigid. Time-varying waveforms were imposed at the model inlets (two vertebral and two internal carotid arteries) based on previously characterized flow waveforms in this area of vasculature. ${ }^{10}$ Three-element Windkessel model representations were prescribed at the six outlets of the model (two anterior, two middle, and two posterior cerebral arteries) to match the flow distribution in the Circle of Willis. ${ }^{50}$

Vascular remodeling is known to occur in areas of elevated WSS. The area of the impact zone (TAWSS $>20 \mathrm{dyn} / \mathrm{cm}^{2}$ ) created by velocity impinging on the aneurysm surface was quantified in addition to the area of low TAWSS $<4 \mathrm{dyn} / \mathrm{cm}^{2} .{ }^{13,31}$ Other CFD studies of cerebral stent performance have calculated flow through a plane across the neck of the aneurysm in order to quantify the turnover rate of blood in the aneurysm, which is indicative of the bulk flow stasis with the aneurysm. ${ }^{2}$ Due to the abnormal geometry of the current aneurysm, it was difficult to define a plane that could be used for this purpose. To quantify flow stasis, each model was virtually clipped at

Annals of Biomedical Engineering, Vol. 39, No. 5 (May 2011): pg. 1423-1437. DOI. This article is @ Springer and permission has been granted for this version to appear in e-Publications@Marquette. Springer does not grant permission for this article to be further copied/distributed or hosted elsewhere without the express permission from Springer. 
both ends of the stented region to isolate the aneurysm following simulation and convergence. MET was then computed as previously described by releasing particles at the inlet of the isolated geometry. The cumulative distribution function (CDF) of the MET within the clipped volume was computed in order to quantify bulk flow characteristics within the aneurysm region. The CDF was constructed by calculating the fraction of volume less than a specific threshold and incrementing the threshold $0.0025 \mathrm{~s} / \mathrm{cm}$ between 0 and $0.4 \mathrm{~s} / \mathrm{cm}$ within the isolated region. From the CDF, the probability density function (PDF) of MET was also constructed.

Turbulence within the cerebral aneurysm models was investigated by quantifying the cycle-to-cycle variation within the velocity field as previously described. ${ }^{27}$ Once the simulations were considered converged, four more cardiac cycles were simulated, resulting in five well-converged cycles. An ensemble average for each time point within the cardiac cycle was then computed over the last five cycles. Subtracting the ensemble averaged cycle from the original velocity field results in the fluctuating component of the velocity, $\overrightarrow{\tilde{u}}(\vec{x}, t)$. Mathematically, the fluctuating velocity field can be used to compute the turbulent kinetic energy as:

$$
\operatorname{TKE}(\vec{x}, s)=\frac{1}{2} \rho\left[\left\langle\tilde{u}_{1}^{2}\right\rangle(\vec{x}, s)+\left\langle\tilde{u}_{2}^{2}\right\rangle(\vec{x}, s)+\left\langle\tilde{u}_{3}^{2}\right\rangle(\vec{x}, s)\right], \quad \forall s \in[0, T)
$$

where $T$ is the length of the cardiac cycle, $p$ is the density of blood equal to $1.06 \mathrm{~g} / \mathrm{cm}^{3}$, and $\tilde{u}_{1}, \tilde{u}_{2}$, and $\tilde{u}_{3}$ represents the $x, y$, and $z$ components of the fluctuating velocity, and $\langle\cdot\rangle$ denotes the ensemble mean. We also computed the ensemble averaged kinetic energy (KE) as:

$$
\mathrm{KE}(\vec{x}, s)=\frac{1}{2} \rho\left[\left\langle u_{1}^{2}\right\rangle(\vec{x}, s)+\left\langle u_{2}^{2}\right\rangle(\vec{x}, s)+\left\langle u_{3}^{2}\right\rangle(\vec{x}, s)\right], \quad \forall s \in[0, T)
$$

where $\tilde{u}_{1}, \tilde{u}_{2}$, and $\tilde{u}_{3}$ represents the $x, y$, and $z$ components of the ensemble averaged velocity. Finally, the ratio of TKE/KE was computed at peak systole.

Annals of Biomedical Engineering, Vol. 39, No. 5 (May 2011): pg. 1423-1437. DOI. This article is (C) Springer and permission has been granted for this version to appear in e-Publications@Marquette. Springer does not grant permission for this article to be further copied/distributed or hosted elsewhere without the express permission from Springer. 
NOT THE PUBLISHED VERSION; this is the author's final, peer-reviewed manuscript. The published version may be accessed by following the link in the citation at the bottom of the page.

\section{Results}

A total of five stented models (two coronary, three cerebral) were created using the described method of stent implantation along with corresponding unstented models of each portion of vasculature investigated. The time to create each stented model varied depending on the complexity of the stent design and vessel geometry. The stent creation and implantation into previously built vessel geometries was accomplished in 12-16 $\mathrm{h}$ for each coronary stent and the $\mathrm{N} 2-8 \times 8$

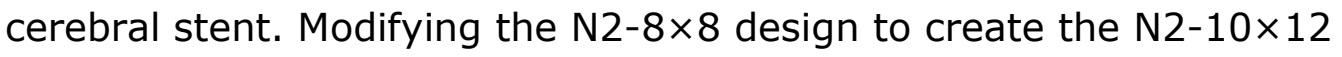
and N2-12×16 designs took about 45 min per model. Using 48 cores of an Intel Nehalem cluster with $3 \mathrm{~GB}$ of RAM per core and InfiniBand interconnects, CFD simulations of the final stented coronary meshes (3.2 million elements) took about $2.9 \mathrm{~h}$ per cardiac cycle, whereas the unstented coronary geometry (2.2 million elements) took $1.75 \mathrm{~h}$ per cardiac cycle. Using 64 cores, the final meshes of the stented (3.1 million elements) and unstented cerebral models (3.1 million elements) were simulated in 2.3 and $1.8 \mathrm{~h}$ per cardiac cycle, respectively.

\section{Coronary Stenting}

Distributions of TAWSS in the coronary arteries for the two stent types are illustrated in Fig. 3. The main branch stent struts induced non-uniform distributions of WSS in the side branch immediately distal to the stent (Fig. 3, epicardial and myocardial insets). Regions of low TAWSS ( $<4 \mathrm{dyn} / \mathrm{cm}^{2}$ ) were localized near the struts and more prevalent distal to the bifurcation in both stent models. The total intrastrut area of the lumen exposed to low TAWSS was higher for the open-cell ring-and-link design (Stent A) $(75.6 \%)$ than the close-cell slotted tube design (Stent B) (59.3\%). The curvature of the model caused localized areas of low TAWSS along the myocardial side of the LAD lumen in both models. Analysis of the unstented model (results not shown) revealed the amount of lumen exposed to low TAWSS due to native vessel geometry is $5.8 \%$, thus the amount of stent-induced low TAWSS is 69.8 and $53.5 \%$. There were only modest differences in the area of the luminal surface exposed to high OSI between the two stent models ( $<1 \%$ for both models), but localized areas of high OSI

Annals of Biomedical Engineering, Vol. 39, No. 5 (May 2011): pg. 1423-1437. DOI. This article is @ Springer and permission has been granted for this version to appear in e-Publications@Marquette. Springer does not grant permission for this article to be further copied/distributed or hosted elsewhere without the express permission from Springer. 
were found to correspond to areas of low TAWSS along the myocardial lumen surface just distal to the bifurcation.

Displacement of the wall in the intrastrut region was 10 times less than that in other portions of the LAD (Fig. 3). The larger opencell geometry of Stent A allowed for a greater intrastrut peak displacement. However, the closed-cell design of Stent B allowed for a greater average circumferential wall strain due to the pattern of wall deformation within the intrastrut region (0.0035 vs. 0.0040). These values were much less than the strain of vessel wall distal to the stent which was near 0.03 .

Approximately 6.2 million particles were released in each bifurcation model over the course of one cardiac cycle and tracked for an additional 19 cardiac cycles to compute MET. Stent implantation increased the region of high MET near the wall of the vessel in the main branch (Fig. 4, bifurcation plane and cross-section A). The most pronounced difference in MET due to stent implantation was in the side branch, just distal to the stent (Fig. 4, cross-section B). In this region, the MET mimicked the stent design, placement, and number of struts in the side branch which caused MET near the center of the vessel to increase relative to the unstented model. Approximately $1.25 \mathrm{~mm}$ distal to cross-section B the MET field of the stented models reflected that of the unstented model, with only slight differences in area of high MET near the vessel wall. The MET was lowest near the carina of the bifurcation which corresponds to increased velocity in this region.

\section{Cerebral Stenting}

Peak systolic velocity, TAWSS, and peak systolic TKE for the three cerebral aneurysm stent designs are shown in Fig. 5. Peak systolic velocity in the dome of the aneurysm decreased as stent filament (i.e., linkage) size decreased, as well as the size of the high velocity jets through the stent. Decreasing filament size also reduced TAWSS on the distal wall of the aneurysm, and caused the area of high TAWSS to move from the dome of the aneurysm towards the neck. The area of the impact zone (TAWSS $>20 \mathrm{dyn} / \mathrm{cm}^{2}$ ) was 7.2, 3.2, 2.6, and $1.7 \%$ of the total aneurysm lumen area for the unstented, N2$8 \times 8, \mathrm{~N} 2-10 \times 12$, and N2-12×16, respectively. Similarly, the area of

Annals of Biomedical Engineering, Vol. 39, No. 5 (May 2011): pg. 1423-1437. DOI. This article is (C) Springer and permission has been granted for this version to appear in e-Publications@Marquette. Springer does not grant permission for this article to be further copied/distributed or hosted elsewhere without the express permission from Springer. 
Iow TAWSS ( $<4$ dyn $/ \mathrm{cm}^{2}$ ) was $33.9,55.4,59.3$, and $64.9 \%$. Qualitatively, the TKE in the aneurysm was minimal throughout the cardiac cycle. Only mildly unsteady flow was present during peak systole. Volume rendered TKE showed no apparent relationship between the TKE and stent filament size (Fig. 5). Similarly, mean TKE values, measured in the stented region (Table 2 ) do not indicate a trend consistent with the observed decreases in velocity and TAWSS. The unstented geometry had the largest TKE, the N2-12×16 had the lowest TKE, but the $\mathrm{N} 2-10 \times 12$ and $\mathrm{N} 2-8 \times 8$ have similar values of TKE. The basilar artery proximal to the aneurysm had a diameter of $3.6 \mathrm{~mm}$ and computed peak and mean Reynolds numbers $(R e)$ of 472 and 240 over the cardiac cycle, respectively.

Mean exposure time within the unstented aneurysm model and the model stented with the N2-12×16 stent are shown in Fig. 6 . Similar to the coronary MET calculation, 6.9 million particles were released over the course of one cardiac cycle and tracked from an additional 19 cardiac cycles for each model. The greatest increase in MET was near the wall of the model and in the middle of the aneurysm. The stent struts also induced a small area of high MET near the stent/lumen interface (Fig. 6, cross-section B of the N2-12×16). The MET field of the N2-8 $\times 8$ and N2-10 $\times 12$ (results not shown) exhibited similar patterns of MET to those in the unstented and $\mathrm{N} 2-12 \times 16$, with magnitudes greater than the unstented and less than the N2-12×16 models. Figure 7 illustrates the changes in the PDF and CDF of the MET field within the stented and aneurysm region for the various cerebral models. With decreased stent filament size, the PDF shifts towards larger higher MET values. The CDF also indicates the unstented model has the highest volume of low MET, whereas the stented models have decreased volumes of low MET.

\section{Discussion}

The newly described virtual stenting method provides a rapid and robust means for evaluating the performance of commercially available and next-generation stents in patient-specific geometries using CFD. The complexity of the coronary bifurcation and large basilar trunk aneurysm models demonstrates the applicability of these methods across vascular beds. Though the CFD results were quantified using

Annals of Biomedical Engineering, Vol. 39, No. 5 (May 2011): pg. 1423-1437. DOI. This article is (C) Springer and permission has been granted for this version to appear in e-Publications@Marquette. Springer does not grant permission for this article to be further copied/distributed or hosted elsewhere without the express permission from Springer. 
some custom computer programs, the model creation and stent implantation process was completed using only commercially available CAD packages already frequently used by stent design engineers and open source software. The method provides a process and examples of results that were previously difficult or laborious to obtain. Localized changes in indices known to correlate with restenosis including WSS can now be obtained for almost any conceivable stent design. Results not often reported such as intrastrut displacement due to differences in stent-induced scaffolding or parameterized contributions of design features to flow stasis can also be obtained rapidly.

Both vascular geometry and stent design are known to influence the post-procedural outcomes of stenting in most diseases treated by stenting. The method of virtual stent implantation employed in this investigation demonstrates a means of representing a complex vessel and full stent geometry to further understand the hemodynamic interactions between them. It is worth noting that other ways of virtually implanting stents into patient-specific vessels have been developed previously, ${ }^{2,17}$ but the series of Boolean operations described here are computationally inexpensive to include and ensure the stent model is in good apposition to the vessel wall.

Using the methods outlined in this investigation, most commercially available and next-generation stents could be modeled with the exception of braided stents with a circular strut profile or other more complicated strut profiles. Stents with complex strut profiles could be generated using the same modeling techniques described in this investigation when simulating blood flow through ideal vessels, but implanting these stents in a patient-specific geometry in which the dimensions of the vessel are not well defined is not possible using the current methods. Nevertheless, the current virtual stenting process provides a framework for rapidly producing and analyzing various stent designs. In this investigation, the deployed configuration of the each stent design was modeled as using parametric design techniques enabling rapid generation of several variations for a particular stent design. Modeling the stent in a deployed configuration further decreased the amount of time necessary to numerically compute the expanded configuration of the stent. Three cerebral aneurysm stent models were all generated from

Annals of Biomedical Engineering, Vol. 39, No. 5 (May 2011): pg. 1423-1437. DOI. This article is (C Springer and permission has been granted for this version to appear in e-Publications@Marquette. Springer does not grant permission for this article to be further copied/distributed or hosted elsewhere without the express permission from Springer. 
the same basic design that was created and virtually implanted in the aneurysm model within a few hours after establishing the variables for use with the initial stent geometry. Given that generating, modifying, and virtual implanting a stent design using the current method can be performed quickly, this process of stent modeling is well-suited for design optimization.

In addition to presenting a novel technique of stent implantation, our results demonstrate post-processing techniques of CFD data which enable a better understanding of flow dynamics within stented geometries. Computation of MET provides insight into changes in bulk flow characteristics within a volume of interest (Fig. 7) and pinpoints specific locations of flow stasis (Figs. 4, 6), whereas metrics like aneurysm turnover rate only provide information about bulk flow. The ability to identify local regions of stagnation is useful understanding disease progression as demonstrated by Rayz et al. ${ }^{42}$ who used a "virtual ink" technique to measures of local areas of flow stasis and found the combination of flow stasis and low WSS was a better predictor of thrombus formation within intracranial aneurysms than either of the two predictors alone. Using the coronary stenting models, we also show an unwrapping technique that facilitates the visualization and comparison of CFD results, such as TAWSS and displacement, within stented regions in a manner similar to that described by Antiga et al. ${ }^{1}$

Several properties of coronary stent design influence local hemodynamics within the coronary vasculature, such as strut size, width, deployments ratio, etc. ${ }^{21,44}$ In this study, the area of low WSS, an indicator for the localization of neointimal hyperplasia, was determined to be greater for the open-cell ring-and-link design (Stent A). Since strut radial thickness and deployment ratio were kept constant for both stent designs, the higher WSS of the closed-cell slotted tube design (Stent B) is likely the result of a longitudinal stent strut angle which is more aligned in the primary blood flow direction. ${ }^{23}$

Using circumferential strain as a measure of the wall motion, Stent B allowed for slightly more wall motion than Stent A. Although somewhat counter-intuitive since initial visual inspection of calculated wall displacement indicated Stent A had higher peak displacement, the

Annals of Biomedical Engineering, Vol. 39, No. 5 (May 2011): pg. 1423-1437. DOI. This article is @ Springer and permission has been granted for this version to appear in e-Publications@Marquette. Springer does not grant permission for this article to be further copied/distributed or hosted elsewhere without the express permission from Springer. 
longer longitudinal length of the stent cell geometry of the prototype stent allows for a greater amount of strain to be generated in intrastrut regions. It should be noted the vessel was modeled with a constant compliance throughout the geometry, but compliance may vary spatial due to the presence of atherosclerotic lesions.

MET in the side branch just distal to the coronary stent is highly influenced by both the stent design and stent position (Fig. 4, crosssection B), and it is difficult to predict which stent design performs best. Interestingly, the difference in MET due to struts crossing the side branch is quite diminished $1.25 \mathrm{~mm}$ distal to the stent (Fig. 4, cross-section $\mathrm{C}$ ), and it is unknown if the small volume of high flow stasis within this region is hemodynamically significant. While we did not consider the effects of stent position in this investigation, Williams et al. ${ }^{60}$ modeled a worst case and best case stent position across the side branch in an ideal model and observed minimal changes in hemodynamics between the models. Future patient studies are likely needed to better understand the affects of the stent position on disease progression within stented bifurcations. The method of stent implantation demonstrated in this investigation is well-suited for investigating stent positions due to the control the user has during stent placement.

Within the cerebral aneurysm model, the velocity, MET, and WSS results indicate that stent implantation increases flow stasis, and decreased stent strut size further increases flow stasis within the aneurysm. Though the porosity of each stent was identical, velocity within the aneurysm decreased as the stent strut size decreased and reduced the area of the impact zone while increasing the area of low TAWSS. None of the stent designs completely eliminated the impact zone, so it is likely vascular remodeling would degrade the aneurysm wall in this region. Interestingly, the magnitude of TAWSS in the impact zone is similar to that in the basilar artery proximal to the aneurysm, but the tissue response to the WSS stimuli is likely different. Recently Meng et al. ${ }^{32}$ induced basilar aneurysms in rabbits and found that diseased tissue within an aneurysm continues expanding and remodeling even after the hemodynamic stimulus that initiated aneurysm formation is removed, unlike healthy vascular

Annals of Biomedical Engineering, Vol. 39, No. 5 (May 2011): pg. 1423-1437. DOI. This article is (C) Springer and permission has been granted for this version to appear in e-Publications@Marquette. Springer does not grant permission for this article to be further copied/distributed or hosted elsewhere without the express permission from Springer. 
tissue which ceases to remodel once stress levels return to a preferred physiologic level.

The results did not indicate any relationship between TKE and stent design. Overall the low $R e$ and very small TKE values in each aneurysm geometry indicates that blood flow in the aneurysm is quite steady, so it is difficult to draw any conclusion about chaotic blood flow in this region. If blood flow to this region were increased by simulating exercising conditions, differences among the stent designs may be more apparent.

The current findings coincide with those of Lieber et al. ${ }^{28}$ who showed that decreased filament size correlated with improved hemodynamic results in a previous PIV study of helical stents. However, this previous study also observed pronounced stent movement with very small filament size which caused increased circulation within the aneurysm for the smallest filament size considered. By modeling the stent as rigid, stent motion was not considered in the current investigation. Another previous PIV study of twenty different stent models, including helical stents, ring-and-link stents, etc., was unable to determine a simple relationship between either stent porosity or stent strut size with stent performance. ${ }^{3}$ Since this work was able to quantify the effects of strut size at a constant porosity, future work may include repeating this study with the same basic designs, but using parametric modeling techniques to model three stents with identical strut size, allowing the porosity of the stents to vary. In this manner, it might be possible to identify which stent design parameters have the greatest influence on stent performance in cerebral aneurysms.

The current results should be interpreted within the constraints of several potential limitations. Notably, our stent implantation method does not model the mechanical interaction between the stent and the vessel during stent deployment. Accurately modeling stent deployment would require more extensive computations and knowledge of stent geometry and material along with the vessel geometry and morphology, which can be difficult to obtain in vivo. The methodology we have described does not account for compliance mismatch between the stent and vessel wall which often causes vessel straightening in

Annals of Biomedical Engineering, Vol. 39, No. 5 (May 2011): pg. 1423-1437. DOI. This article is @ Springer and permission has been granted for this version to appear in e-Publications@Marquette. Springer does not grant permission for this article to be further copied/distributed or hosted elsewhere without the express permission from Springer. 
curved vessels, ${ }^{35,58,61}$ asymmetric stent deformation across aneurysm necks or branching arteries, ${ }^{6,14}$ kinking of the stent in regions of acute curvatures, ${ }^{6}$ vessel prolapse into the flow domain, ${ }^{4,22,36}$ or stent malapposition. ${ }^{4}$ From previous CFD studies of the coronary arteries with and without straightening induced by stenting, we would expect extreme changes in curvature near the proximal and distal ends of stent may induce harmful distributions of WSS that leads to restenosis. ${ }^{25}$ Vessel prolapse has been incorporated into idealized CFD models of commercial stents and was found to decrease the amount of the vessel exposed to low WSS. ${ }^{36}$ Conversely, previous idealized models ${ }^{22}$ and a more recent study of stent deployment in a canine artery ex vivo ${ }^{4}$ have found that prolapse of the vessel into the flow domain increased levels of WSS; therefore hemodynamic alterations due to vessel prolapse likely depends on the stent design and how prolapse is modeled. The ex vivo canine model of Benndorf et al. ${ }^{4}$ was also used to study stent malapposition in straight vessels and identified increased low WSS distal to the malapposition. Although our method of stent implantation does not account for the stent/vessel interactions discussed above, visiual comparison of the coronary model in this investigation to the Benndorf et al. canine model indicates that deviations from reality appear to be modest when this method is used in a relatively straight geometry. In vessels of acute curvature, the inability to predict changes in wall curvature and stent kinking are inherent limitations of our method. Future research on the virtually stent implantation methodology will work to address these limitations.

Most of the limitations of the virtual stenting method in this investigation are only valid when creating a priori models of stenting procedure. The method can also be used to reconstruct a patientspecific geometry post-stent implantation with much greater accuracy since the final geometry of the deployed stent and associated vessel is known. For example, using high resolution imaging data, such as optical coherence tomography, of a deployed stent, the stent boundaries and vessel lumen can be segmented and lofted separately to create two distinct models. Then the virtual stenting procedure can be used to implant the stent in only the model of the lofted stent boundaries. Subtracting the implanted stent model from the lumen model creates an accurate model of the stented vessel, which includes vessel prolapse, thrombosis, stent malapposition, and other vascular

Annals of Biomedical Engineering, Vol. 39, No. 5 (May 2011): pg. 1423-1437. DOI. This article is (C Springer and permission has been granted for this version to appear in e-Publications@Marquette. Springer does not grant permission for this article to be further copied/distributed or hosted elsewhere without the express permission from Springer. 
features because using two separate models for the stent and lumen does not confine the stent to being well apposed to the lumen. Using this modeling technique, the stent position is represented as it appears in vivo with the only limitation being the inability to model small nonuniform expansion of stent cells.

Modeling large portions of the vasculature in addition to a stent made it difficult to achieve mesh independence as defined by a change in time-averaged WSS at predetermined proximal and distal intrastrut $<0.09 \mathrm{dyn} / \mathrm{cm}^{2}$ between successive meshes. In the coronary stenting simulation, this level of accuracy was achieved with $\sim 3$ million elements, but was not attainable in the cerebral aneurysm models due to the computational limitations of generating large meshes for vessels over such a wide range of sizes. Therefore, conclusions regarding intrastrut distributions of TAWSS were not made for these models. Measured levels of TAWSS within a $1.5 \mathrm{~mm}$ thick slice of the model proximal and distal to the stent changed by $<1 \%$ for the cerebral aneurysm model. Though mesh independence was not attained as defined, stent struts extending across the neck of the cerebral aneurysm had $>5$ elements across their face for simulations with the densest meshes.

In summary, the current investigation describes an efficient method for virtual stent implantation in patient-specific models in order to analyze alterations in hemodynamics using CFD. Unlike idealized computational models of stent designs, this method can be used to quantify differences in stent performance in complex vascular models for most stenting procedures, as demonstrated in this investigation through the construction of two arterial models with varying degrees of complexity. For each model in this investigation, the method of virtual stent implantation was used to quantify the potential impact of partially occluding downstream vascular regions by stent struts and therefore may be used in future studies to investigate various stenting strategies at bifurcations or in response to treatments in order to provide additional insight into ways of optimizing stents for particular portions of the vasculature.

Annals of Biomedical Engineering, Vol. 39, No. 5 (May 2011): pg. 1423-1437. DOI. This article is (C) Springer and permission has been granted for this version to appear in e-Publications@Marquette. Springer does not grant permission for this article to be further copied/distributed or hosted elsewhere without the express permission from Springer. 
NOT THE PUBLISHED VERSION; this is the author's final, peer-reviewed manuscript. The published version may be accessed by following the link in the citation at the bottom of the page.

\section{Acknowledgments}

This work is supported by a Translational Opportunity Grant of the Pilot and Collaborative Clinical and Translational Research Grants program from the Clinical and Translational Science Institute of Southeastern Wisconsin and computational support or this work was made possible by NSF grants CTS-0521602 and OCI-0923037. Dr. Bon-Kwon Koo is the recipient of a research grant from the CardioVascular Research Foundation (CVRF), Korea. The authors recognize Nathan Wilson Ph.D. of Open Source Medical Software Corporation for technical assistance.

\section{References}

1. Antiga, L., and D. A. Steinman. Robust and objective decomposition and mapping of bifurcating vessels. IEEE Trans. Med. Imaging 23:704$713,2004$.

2. Appanaboyina, S., F. Mut, R. Lohner, C. M. Putman, and J. R. Cebral. Computational fluid dynamics of stented intracranial aneurysms using adaptive embedded unstructured grids. Int. J. Numer. Methods Fluid. 57:475-493, 2008.

3. Barath, K., F. Cassot, J. H. Fasel, M. Ohta, and D. A. Rufenacht. Influence of stent properties on the alteration of cerebral intra-aneurysmal haemodynamics: flow quantification in elastic sidewall aneurysm models. Neurol. Res. 27(Suppl 1):S120-S128, 2005.

4. Benndorf, G., M. Ionescu, M. Valdivia y Alvarado, A. Biondi, J. Hipp, and R. Metcalfe. Anomalous hemodynamic effects of a self-expanding intracranial stent: comparing in vitro and ex vivo models using ultrahigh resolution microct based cfd. J. Biomech. 43:740-748, 2010.

5. Berry, J. L., E. Manoach, C. Mekkaoui, P. H. Rolland, J. E. Moore, Jr., and A. Rachev. Hemodynamics and wall mechanics of a compliance matching stent: in vitro and in vivo analysis. J. Vasc. Interv. Radiol. 13:97-105, 2002.

6. Ebrahimi, N., B. Claus, C. Y. Lee, A. Biondi, and G. Benndorf. Stent conformity in curved vascular models with simulated aneurysm necks using flat-panel ct: an in vitro study. AJNR Am. J. Neuroradiol. 28:823-829, 2007.

7. Figueroa, C. A., I. E. Vignon-Clementel, K. E. Jansen, T. J. R. Hughes, and C. A. Taylor. A coupled momentum method for modeling blood flow in three-dimensional deformable arteries. Comput. Methods Appl. Mech. Eng. 195:5685-5706, 2006.

Annals of Biomedical Engineering, Vol. 39, No. 5 (May 2011): pg. 1423-1437. DOI. This article is (C) Springer and permission has been granted for this version to appear in e-Publications@Marquette. Springer does not grant permission for this article to be further copied/distributed or hosted elsewhere without the express permission from Springer. 
8. Finet, G., M. Gilard, B. Perrenot, G. Rioufol, P. Motreff, L. Gavit, and R. Prost. Fractal geometry of arterial coronary bifurcations: a quantitative coronary angiography and intravascular ultrasound analysis. EuroIntervention 3:490-498, 2007.

9. Finn, A. V., G. Nakazawa, M. Joner, F. D. Kolodgie, E. K. Mont, H. K. Gold, and R. Virmani. Vascular responses to drug eluting stents: importance of delayed healing. Arterioscler. Thromb. Vasc. Biol. 27:1500-1510, 2007.

10. Ford, M. D., N. Alperin, S. H. Lee, D. W. Holdsworth, and D. A. Steinman. Characterization of volumetric flow rate waveforms in the normal internal carotid and vertebral arteries. Physiol. Meas. 26:477-488, 2005.

11. Garasic, J. M., E. R. Edelman, J. C. Squire, P. Seifert, M. S. Williams, and C. Rogers. Stent and artery geometry determine intimal thickening independent of arterial injury. Circulation 101:812-818, 2000.

12. He, X., and D. N. Ku. Pulsatile flow in the human left coronary artery bifurcation: average conditions. J. Biomech. Eng. 118:74-82, 1996.

13. Hoi, Y., H. Meng, S. H. Woodward, B. R. Bendok, R. A. Hanel, L. R. Guterman, and L. N. Hopkins. Effects of arterial geometry on aneurysm growth: three-dimensional computational fluid dynamics study. J. Neurosurg. 101: 676-681, 2004.

14. Hsu, S. W., J. C. Chaloupka, J. A. Feekes, M. D. Cassell, and Y. F. Cheng. In vitro studies of the neuroform microstent using transparent human intracranial arteries. AJNR Am. J. Neuroradiol. 27:1135-1139, 2006.

15. Iakovou, I., T. Schmidt, E. Bonizzoni, L. Ge, G. M. Sangiorgi, G. Stankovic, F. Airoldi, A. Chieffo, M. Montorfano, M. Carlino, I. Michev, N. Corvaja, C. Briguori, U. Gerckens, E. Grube, and A. Colombo. Incidence, predictors, and outcome of thrombosis after successful implantation of drug-eluting stents. JAMA 293:2126-2130, 2005.

16. Kang, W. C., K. J. Oh, S. H. Han, T. H. Ahn, and E. K. Shin. Progression of dissection due to residual dissection after intracoronary stenting for spontaneous coronary dissection at bifurcation site of lad and diagonal artery. Int. J. Cardiol. 125:e40-e43, 2008.

17. Kim, M., E. I. Levy, H. Meng, and L. N. Hopkins. Quantification of hemodynamic changes induced by virtual placement of multiple stents across a wide-necked basilar trunk aneurysm. Neurosurgery 61:13051312, 2007 (discussion 1312-1303).

18. Kim, M., D. B. Taulbee, M. Tremmel, and H. Meng. Comparison of two stents in modifying cerebral aneurysm hemodynamics. Ann. Biomed. Eng. 36:726-741, 2008.

19. LaDisa, Jr., J. F., D. A. Hettrick, L. E. Olson, I. Guler, E. R. Gross, T. T. Kress, J. R. Kersten, D. C. Warltier, and P. S. Pagel. Coronary stent implantation alters coronary artery hemodynamics and wall shear

Annals of Biomedical Engineering, Vol. 39, No. 5 (May 2011): pg. 1423-1437. DOI. This article is (c) Springer and permission has been granted for this version to appear in e-Publications@Marquette. Springer does not grant permission for this article to be further copied/distributed or hosted elsewhere without the express permission from Springer 
stress during maximal vasodilation. J. Appl. Physiol. 93:1939-1946, 2002.

20. LaDisa, Jr., J. F., I. Guler, L. E. Olson, D. A. Hettrick, J. R. Kersten, D. C. Warltier, and P. S. Pagel. Three-dimensional computational fluid dynamics modeling of alterations in coronary wall shear stress produced by stent implantation. Ann. Biomed. Eng. 31:972-980, 2003.

21. LaDisa, Jr., J. F., L. E. Olson, I. Guler, D. A. Hettrick, S. H. Audi, J. R. Kersten, D. C. Warltier, and P. S. Pagel. Stent design properties and deployment ratio influence indexes of wall shear stress: a threedimensional computational fluid dynamics investigation within a normal artery. J. Appl. Physiol. 97:424-430, 2004.

22. LaDisa, Jr., J. F., L. E. Olson, I. Guler, D. A. Hettrick, J. R. Kersten, D. C. Warltier, and P. S. Pagel. Circumferential vascular deformation after stent implantation alters wall shear stress evaluated using timedependent 3d computational fluid dynamics models. J. Appl. Physiol. 98:947-957, 2005.

23. LaDisa, Jr., J. F., L. E. Olson, D. A. Hettrick, D. C. Warltier, J. R. Kersten, and P. S. Pagel. Axial stent strut angle influences wall shear stress after stent implantation: analysis using $3 \mathrm{~d}$ computational fluid dynamics models of stent foreshortening. Biomed. Eng. Online 4:59, 2005.

24. LaDisa, Jr., J. F., L. E. Olson, R. C. Molthen, D. A. Hettrick, P. F. Pratt, M. D. Hardel, J. R. Kersten, D. C. Warltier, and P. S. Pagel. Alterations in wall shear stress predict sites of neointimal hyperplasia after stent implantation in rabbit iliac arteries. Am. J. Physiol. Heart 288:H2465$\mathrm{H} 2475,2005$.

25. LaDisa, Jr, J. F., L. E. Olson, H. A. Douglas, D. C. Warltier, J. R. Kersten, and P. S. Pagel. Alterations in regional vascular geometry produced by theoretical stent implantation influence distributions of wall shear stress: Analysis of a curved coronary artery using 3d computational fluid dynamics modeling. Biomed. Eng. Online 5:40, 2006.

26. Laskey, W. K., H. G. Parker, V. A. Ferrari, W. G. Kussmaul, and A. Noordergraaf. Estimation of total systemic arterial compliance in humans. J. Appl. Physiol. 69:112-119, 1990.

27. Les, A. S., S. C. Shadden, C. A. Figueroa, J. M. Park, M. M. Tedesco, R. J. Herfkens, R. L. Dalman, and C. A. Taylor. Quantification of hemodynamics in abdominal aortic aneurysms during rest and exercise using magnetic resonance imaging and computational fluid dynamics. Ann. Biomed. Eng. 38:1288-1313, 2010.

28. Lieber, B. B., V. Livescu, L. N. Hopkins, and A. K. Wakhloo. Particle image velocimetry assessment of stent design influence on intra-aneurysmal flow. Ann. Biomed. Eng. 30:768-777, 2002.

Annals of Biomedical Engineering, Vol. 39, No. 5 (May 2011): pg. 1423-1437. DOI. This article is @ Springer and permission has been granted for this version to appear in e-Publications@Marquette. Springer does not grant permission for this article to be further copied/distributed or hosted elsewhere without the express permission from Springer. 
29. Lloyd-Jones, D., R. Adams, M. Carnethon, G. De Simone, T. B. Ferguson, K. Flegal, E. Ford, K. Furie, A. Go, K. Greenlund, N. Haase, S. Hailpern, M. Ho, V. Howard, B. Kissela, S. Kittner, D. Lackland, L. Lisabeth, A. Marelli, M. McDermott, J. Meigs, D. Mozaffarian, G. Nichol, C. O’Donnell, V. Roger, W. Rosamond, R. Sacco, P. Sorlie, R. Stafford, J. Steinberger, T. Thom, S. Wasserthiel-Smoller, N. Wong, J. WylieRosett, and Y. Hong. Heart disease and stroke statistics-2009 update: a report from the American heart association statistics committee and stroke statistics subcommittee. Circulation 119:480-486, 2009.

30. Lonyai, A., A. M. Dubin, J. A. Feinstein, C. A. Taylor, and S. C. Shadden. New insights into pacemaker lead-induced venous occlusion: simulation-based investigation of alterations in venous biomechanics. Cardiovasc. Eng. 10:84-90, 2010.

31. Meng, H., Z. Wang, M. Kim, R. D. Ecker, and L. N. Hopkins. Saccular aneurysms on straight and curved vessels are subject to different hemodynamics: implications of intravascular stenting. AJNR Am. J. Neuroradiol. 27:1861-1865, 2006.

32. Meng, H., E. Metaxa, L. Gao, N. Liaw, S. K. Natarajan, D. D. Swartz, A. H. Siddiqui, J. Kolega, and J. Mocco. Progressive aneurysm development following hemodynamic insult. J. Neurosurg., 2010. doi:10.3171/2010.9. JNS10368.

33. Molyneux, A., R. Kerr, I. Stratton, P. Sandercock, M. Clarke, J. Shrimpton, and R. Holman. International subarachnoid aneurysm trial (isat) of neurosurgical clipping versus endovascular coiling in 2143 patients with ruptured intracranial aneurysms: a randomized trial. J. Stroke Cerebrovasc. Dis. 11:304-314, 2002.

34. Mortier, P., M. De Beule, D. Van Loo, B. Masschaele, P. Verdonck, and B. Verhegghe. Automated generation of a finite element stent model. Med. Biol. Eng. Comput. 46:1169-1173, 2008.

35. Mortier, P., G. A. Holzapfel, M. De Beule, D. Van Loo, Y. Taeymans, P. Segers, P. Verdonck, and B. Verhegghe. A novel simulation strategy for stent insertion and deployment in curved coronary bifurcations: comparison of three drug-eluting stents. Ann. Biomed. Eng. 38:88-99, 2010.

36. Murphy, J., and F. Boyle. Assessment of the effects of increasing levels of physiological realism in the computational fluid dynamics analyses of implanted coronary stents. Conf. Proc. IEEE Eng. Med. Biol. Soc. 2008: 5906-5909, 2008.

37. Myers, J. G., J. A. Moore, M. Ojha, K. W. Johnston, and C. R. Ethier. Factors influencing blood flow patterns in the human right coronary artery. Ann. Biomed. Eng. 29:109- 120, 2001.

Annals of Biomedical Engineering, Vol. 39, No. 5 (May 2011): pg. 1423-1437. DOI. This article is @ Springer and permission has been granted for this version to appear in e-Publications@Marquette. Springer does not grant permission for this article to be further copied/distributed or hosted elsewhere without the express permission from Springer. 
NOT THE PUBLISHED VERSION; this is the author's final, peer-reviewed manuscript. The published version may be

accessed by following the link in the citation at the bottom of the page.

38. O'Rourke, M. F., and M. E. Safar. Relationship between aortic stiffening and microvascular disease in brain and kidney: cause and logic of therapy. Hypertension 46:200- 204, 2005.

39. Perry, R., C. G. De Pasquale, D. P. Chew, L. Brown, P. E. Aylward, and M. $X$. Joseph. Changes in left anterior descending coronary artery wall thickness detected by high resolution transthoracic echocardiography. Am. J. Cardiol. 101:937-940, 2008.

40. Pflederer, T., J. Ludwig, D. Ropers, W. G. Daniel, and S. Achenbach. Measurement of coronary artery bifurcation angles by multidetector computed tomography. Invest. Radiol. 41:793-798, 2006.

41. Radaelli, A. G., L. Augsburger, J. R. Cebral, M. Ohta, D. A. Rufenacht, R. Balossino, G. Benndorf, D. R. Hose, A. Marzo, R. Metcalfe, P. Mortier, F. Mut, P. Reymond, L. Socci, B. Verhegghe, and A. F. Frangi. Reproducibility of haemodynamical simulations in a subject-specific stented aneurysm model-a report on the virtual intracranial stenting challenge 2007. J. Biomech. 41:2069-2081, 2008.

42. Rayz, V. L., L. Boussel, L. Ge, J. R. Leach, A. J. Martin, M. T. Lawton, C. McCulloch, and D. Saloner. Flow residence time and regions of intraluminal thrombus deposition in intracranial aneurysms. Ann.

Biomed. Eng. 38:3058- 3069, 2010.

43. Richter, Y., and E. R. Edelman. Cardiology is flow. Circulation 113:26792682, 2006.

44. Rogers, C., and E. R. Edelman. Endovascular stent design dictates experimental restenosis and thrombosis. Circulation 91:2995-3001, 1995.

45. Ryan, J., and D. J. Cohen. Are drug-eluting stents cost-effective? It depends on whom you ask. Circulation 114:1736-1743, 2006.

46. Sedat, J., Y. Chau, L. Mondot, J. Vargas, J. Szapiro, and M. Lonjon. Endovascular occlusion of intracranial wide-necked aneurysms with stenting (neuroform) and coiling: mid-term and long-term results. Neuroradiology 51:401- 409, 2009.

47. Steinman, D. A., and C. A. Taylor. Flow imaging and computing: large artery hemodynamics. Ann. Biomed. Eng. 33:1704-1709, 2005.

48. Stergiopulos, N., D. F. Young, and T. R. Rogge. Computer simulation of arterial flow with applications to arterial and aortic stenoses. $J$. Biomech. 25:1477-1488, 1992.

49. Stergiopulos, N., P. Segers, and N. Westerhof. Use of pulse pressure method for estimating total arterial compliance in vivo. Am. J. Physiol. 276:H424-H428, 1999.

50. Tanaka, H., N. Fujita, T. Enoki, K. Matsumoto, Y. Watanabe, K. Murase, and $\mathrm{H}$. Nakamura. Relationship between variations in the circle of Willis and flow rates in internal carotid and basilar arteries determined by means of magnetic resonance imaging with semiautomated lumen

Annals of Biomedical Engineering, Vol. 39, No. 5 (May 2011): pg. 1423-1437. DOI. This article is @ Springer and permission has been granted for this version to appear in e-Publications@Marquette. Springer does not grant permission for this article to be further copied/distributed or hosted elsewhere without the express permission from Springer. 
segmentation: reference data from 125 healthy volunteers. AJNR Am. J. Neuroradiol. 27:1770-1775, 2006.

51. Tang, B. T., C. P. Cheng, M. T. Draney, N. M. Wilson, P. S. Tsao, R. J. Herfkens, and C. A. Taylor. Abdominal aortic hemodynamics in young healthy adults at rest and during lower limb exercise: quantification using image-based computer modeling. Am. J. Physiol. Heart Circ. Physiol. 291:H668-H676, 2006.

52. Taylor, C. A., and D. A. Steinman. Image-based modeling of blood flow and vessel wall dynamics: applications, methods and future directions: Sixth International Bio-Fluid Mechanics Symposium and Workshop, March 28-30, 2008 Pasadena, California. Ann. Biomed. Eng. 38:11881203, 2010.

53. Van Belle, E., F. O. Tio, T. Couffinhal, L. Maillard, J. Pesseri, and J. M. Isner. Stent endothelialization: time course, impact of local catheter delivery, feasibility of recombinant protein administration, and response to cytokine expedition. Circulation 95:438-448, 1997.

54. Van Huis, G. A., P. Sipkema, and N. Westerhof. Coronary input impedance during cardiac cycle as determined by impulse response method. Am. J. Physiol. 253:H317-H324, 1987.

55. Vignon-Clementel, I. E., C. A. Figueroa, K. E. Jansen, and C. A. Taylor. Outflow boundary conditions for three-dimensional finite element modeling of blood flow and pressure in arteries. Comput. Methods Appl. Mech. Eng. 195:3776-3796, 2006.

56. Wang, W. Q., D. K. Liang, D. Z. Yang, and M. Qi. Analysis of the transient expansion behavior and design optimization of coronary stents by finite element method. J. Biomech. 39:21-32, 2006.

57. Wanke, I., A. Doerfler, B. Schoch, D. Stolke, and M. Forsting. Treatment of wide-necked intracranial aneurysms with a self-expanding stent system: initial clinical experience. AJNR Am. J. Neuroradiol. 24:11921199, 2003.

58. Wentzel, J. J., D. M. Whelan, W. J. van der Giessen, H. M. van Beusekom, I. Andhyiswara, P. W. Serruys, C. J. Slager, and R. Krams. Coronary stent implantation changes 3-d vessel geometry and 3-d shear stress distribution. J. Biomech. 33:1287-1295, 2000.

59. Westerhof, N., N. Stergiopulos, and M. I. M. Noble. Snapshots of Hemodynamics: An Aid for Clinical Research and Graduate Education. New York, NY: Springer, 2005, 192 pp.

60. Williams, A. R., B. K. Koo, T. J. Gundert, P. J. Fitzgerald, and J. F. LaDisa, Jr. Local hemodynamic changes caused by main branch stent implantation and subsequent virtual side branch balloon angioplasty in a representative coronary bifurcation. J. Appl. Physiol. 109:532-540, 2010.

Annals of Biomedical Engineering, Vol. 39, No. 5 (May 2011): pg. 1423-1437. DOI. This article is (C) Springer and permission has been granted for this version to appear in e-Publications@Marquette. Springer does not grant permission for this article to be further copied/distributed or hosted elsewhere without the express permission from Springer. 
NOT THE PUBLISHED VERSION; this is the author's final, peer-reviewed manuscript. The published version may be accessed by following the link in the citation at the bottom of the page.

61. Wu, W., W. Q. Wang, D. Z. Yang, and M. Qi. Stent expansion in curved vessel and their interactions: a finite element analysis. J. Biomech. 40:2580-2585, 2007.

\section{Appendix}

\section{Figure 1}

(a1)

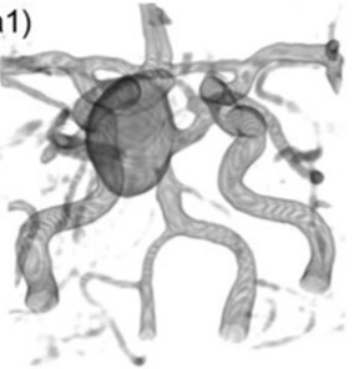

(b1)

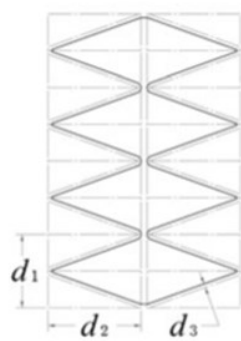

(c1)

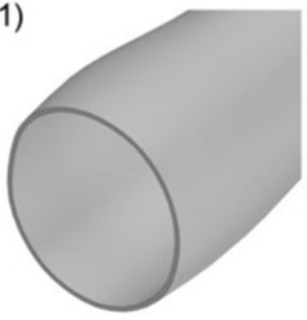

(b2)

(a2)

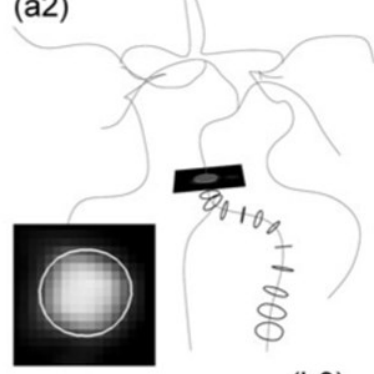

(b3)

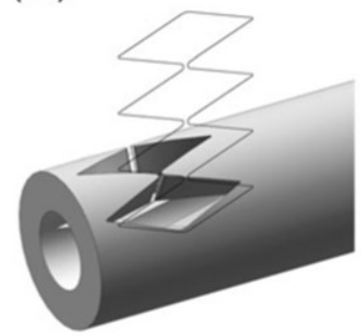

(a3)

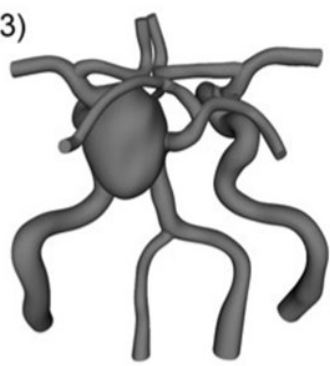

(b4)

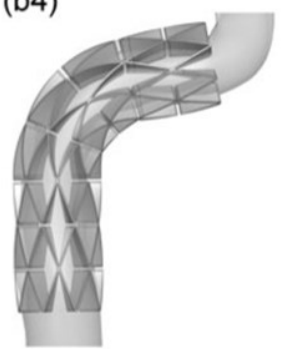

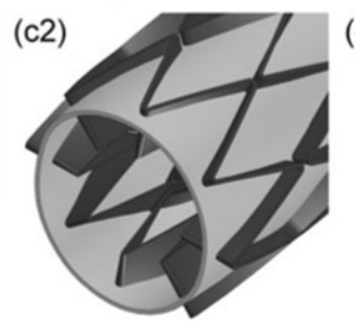

(c3)
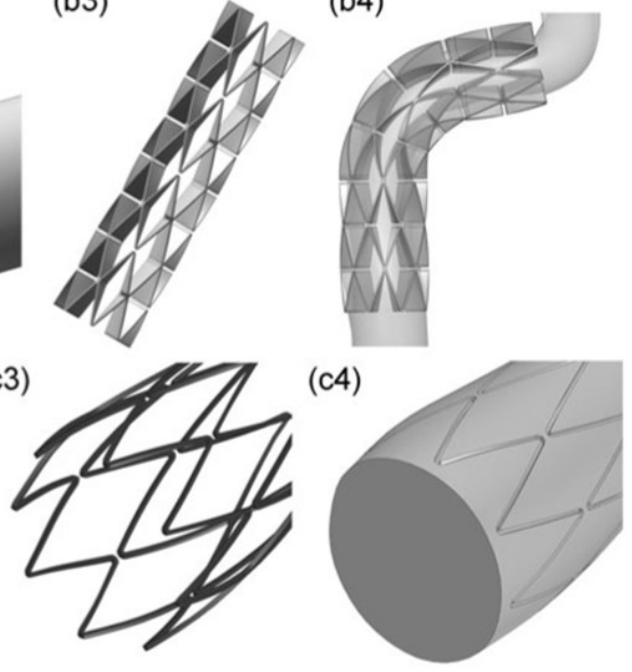

Method of patient-specific model construction. Imaging data, shown as a volume rendering (a1), is used to generate vessel centerlines and 2-D segments of the arterial geometry (a2). The segments were lofted together to create a 3-D solid model (a3). A parameterized sketch of the stent cell (b1) is wrapped around a thick tube (b2) and propagated along the length of the tube to create model of a thick stent (b3). The thick stent is flexed to match the arterial geometry (b4). The solid vessel (c1) is hollowed to radial thickness equal to that of the stent, such that the intersection of the thick model of the stent and thin vessel (c2) yields a patient-specific stent (c3) that is subtracted from the solid model to produce the flow domain (c4). 
NOT THE PUBLISHED VERSION; this is the author's final, peer-reviewed manuscript. The published version may be accessed by following the link in the citation at the bottom of the page.

\section{Figure 2}

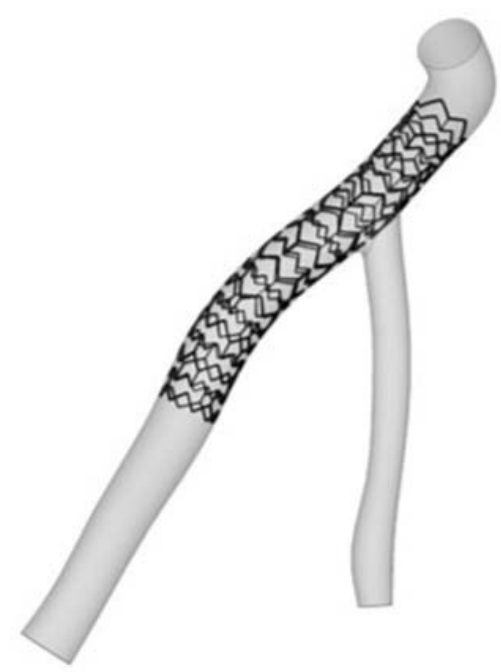

(a)

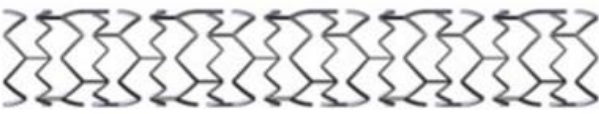

(b)

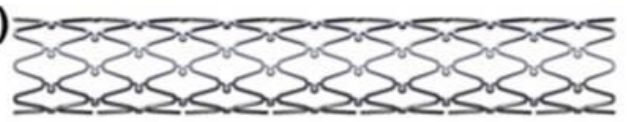

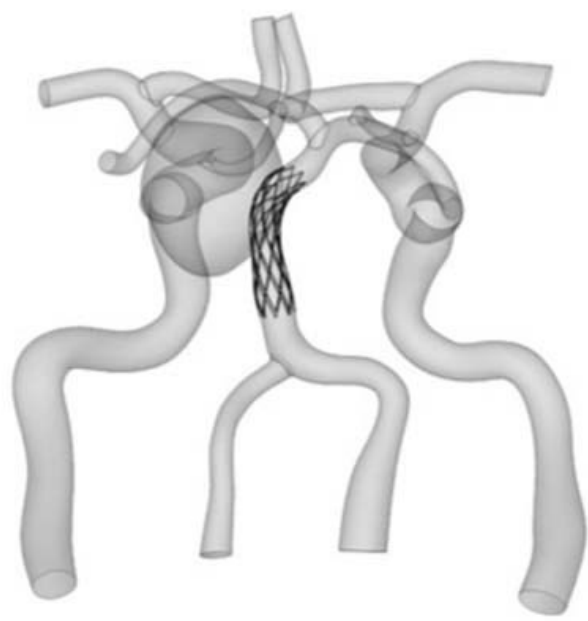

(c)

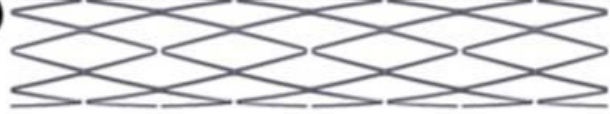

(d)

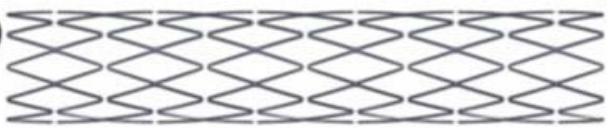

(e)

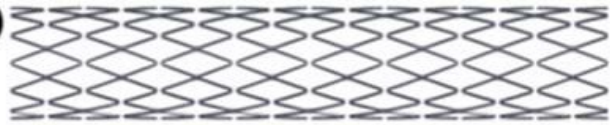

(Left) Coronary model in which and open-cell ring-and-link (a) and a closed-cell slotted tube (b) stent designs were virtually implanted. (Right) Basilar truck aneurysm in which three stent similar to the Neuroform2 (c: N2-838, d: N2-10312, e: N212316) were virtually implanted.

Annals of Biomedical Engineering, Vol. 39, No. 5 (May 2011): pg. 1423-1437. DOI. This article is (C) Springer and permission has been granted for this version to appear in e-Publications@Marquette. Springer does not grant permission for this article to be further copied/distributed or hosted elsewhere without the express permission from Springer. 
NOT THE PUBLISHED VERSION; this is the author's final, peer-reviewed manuscript. The published version may be accessed by following the link in the citation at the bottom of the page.

Figure 3
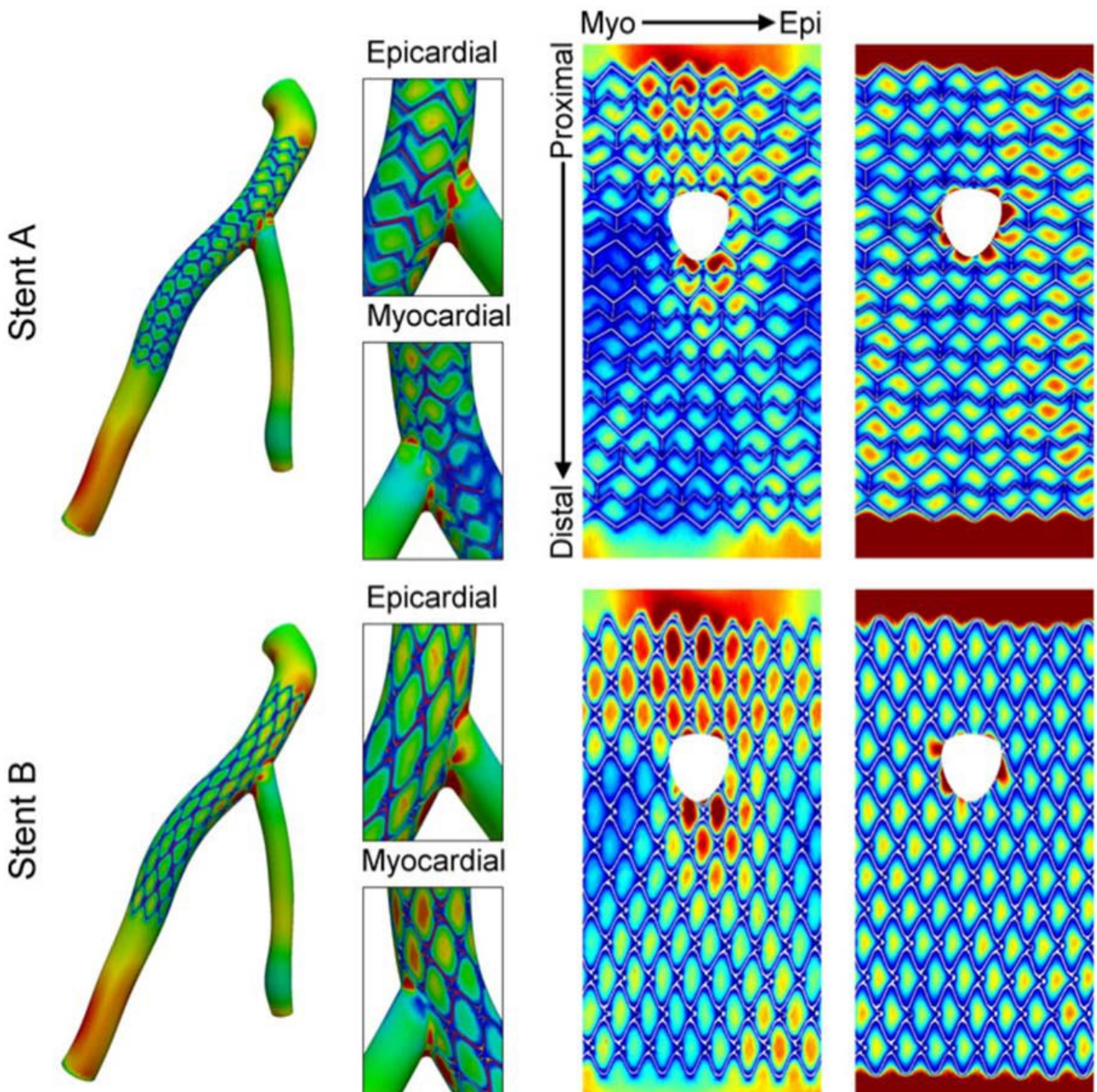

\section{Epicardial}
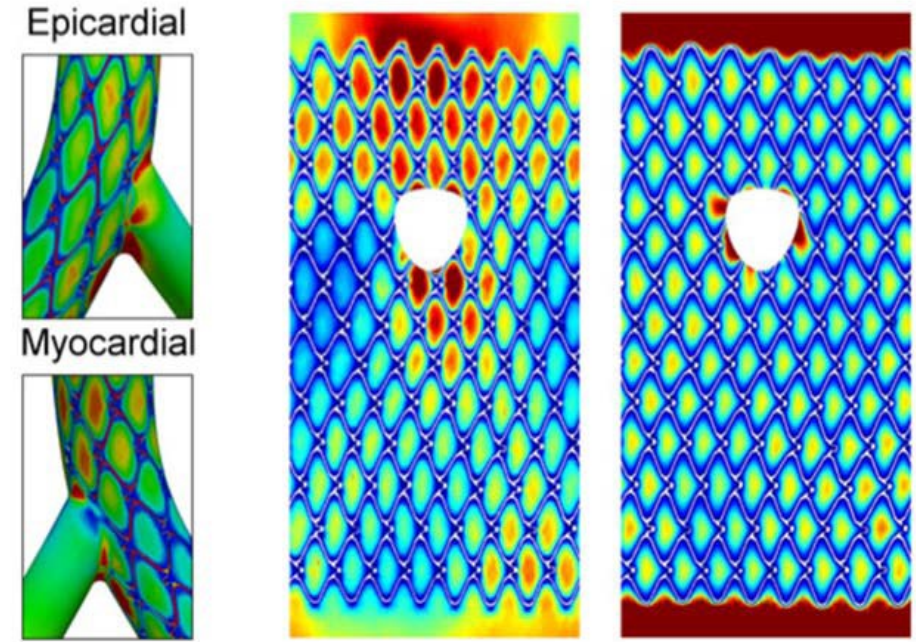

TAWSS (dynes $/ \mathrm{cm}^{2}$ )

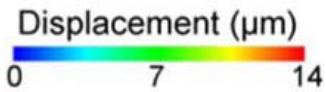

Comparison of hemodynamic indices between the Stent A and Stent B. Time-averaged wall shear stress (TAWSS) is shown on the vessel (Left) and the insets show the distribution at the bifurcation as a result of partial side branch occlusion. The main branch of the vessel was unwrapped to visualize intrastrut TAWSS and vessel wall displacement.

Annals of Biomedical Engineering, Vol. 39, No. 5 (May 2011): pg. 1423-1437. DOI. This article is () Springer and permission has been granted for this version to appear in e-Publications@Marquette. Springer does not grant permission for this article to be further copied/distributed or hosted elsewhere without the express permission from Springer. 
NOT THE PUBLISHED VERSION; this is the author's final, peer-reviewed manuscript. The published version may be accessed by following the link in the citation at the bottom of the page.

\section{Figure 4}
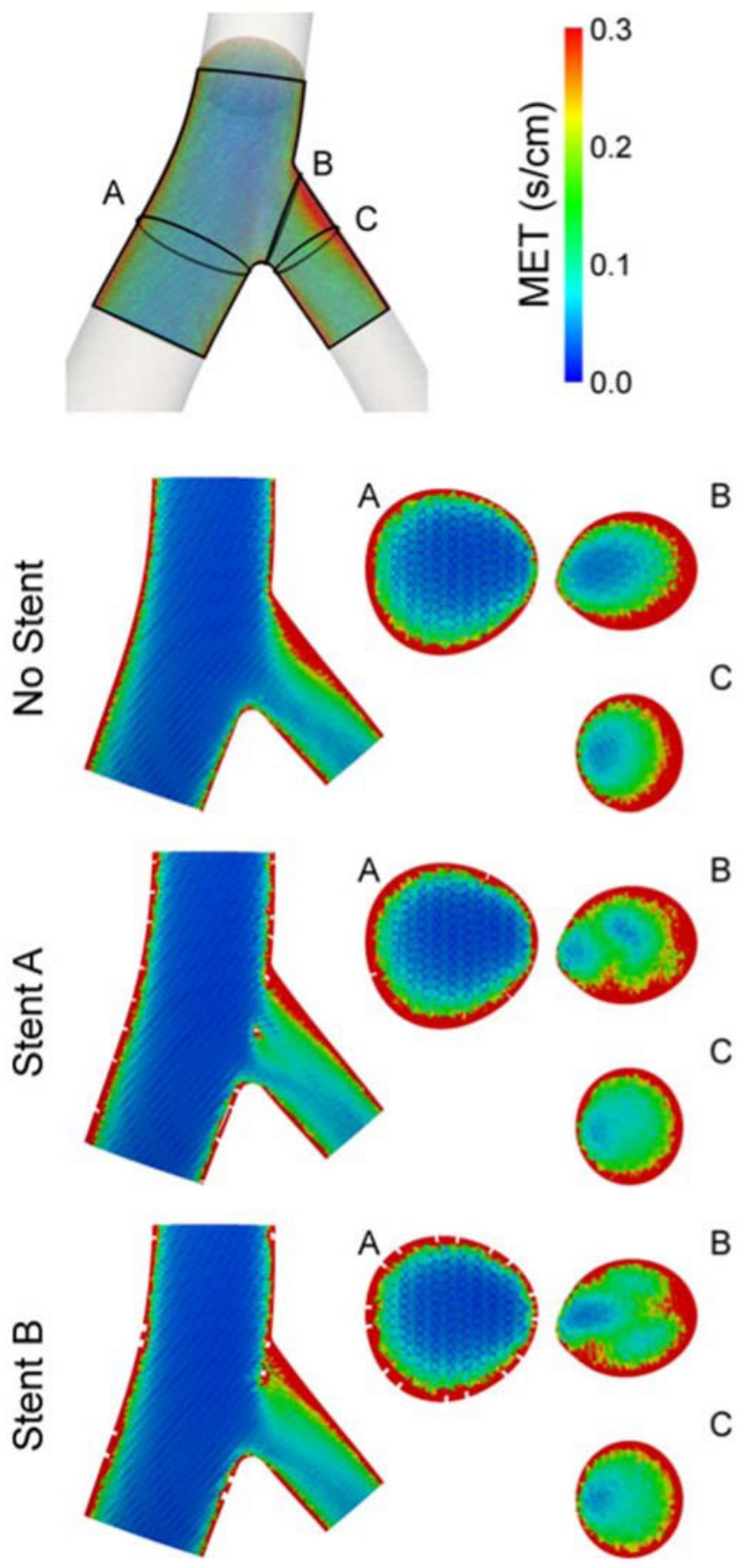

Cross-sections of the mean exposure time (MET) at the coronary bifurcation for one unstented and two stented models. MET is visualized in a plane parallel to the bifurcation and three planes perpendicular to the vessel (Top). The two planes in the sidebranch of the bifurcation (B-C) are separated by a centerline distance of approximately $1.25 \mathrm{~mm}$.

Annals of Biomedical Engineering, Vol. 39, No. 5 (May 2011): pg. 1423-1437. DOI. This article is (C) Springer and permission has been granted for this version to appear in e-Publications@Marquette. Springer does not grant permission for this article to be further copied/distributed or hosted elsewhere without the express permission from Springer. 


\section{Figure 5}
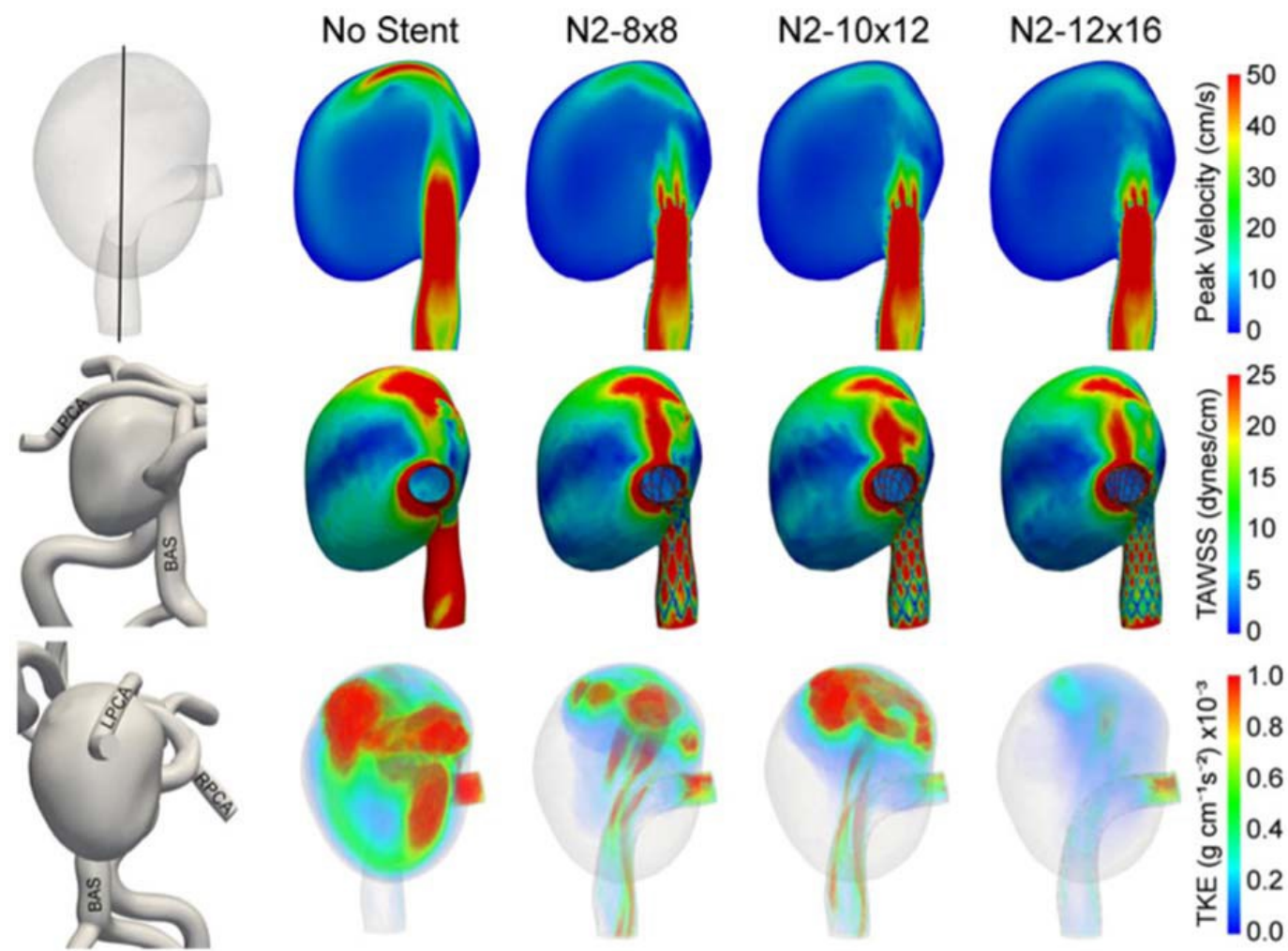

(Top) Magnitude of velocity in a slice in through the center of a cerebral aneurysm and stent during peak systole. (Middle) Time-averaged wall shear stress (TAWSS) on the lumen of the aneurysm visualized on the distal surface of the aneurysm where blood entering the aneurysm impinges on the lumen. (Bottom) Volume rendered turbulent kinetic energy (TKE) in the aneurysm at peak systole. The models on the left illustrate the position of the velocity slice and the perspectives from which TAWSS and TKE were visualized with respect to the basilar (BAS), left posterior cerebral artery (LPCA) and right posterior cerebral artery (RPCA).

Annals of Biomedical Engineering, Vol. 39, No. 5 (May 2011): pg. 1423-1437. DOI. This article is (C Springer and permission has been granted for this version to appear in e-Publications@ Marquette. Springer does not grant permission for this article to be further copied/distributed or hosted elsewhere without the express permission from Springer. 
NOT THE PUBLISHED VERSION; this is the author's final, peer-reviewed manuscript. The published version may be accessed by following the link in the citation at the bottom of the page.

\section{Figure 6}
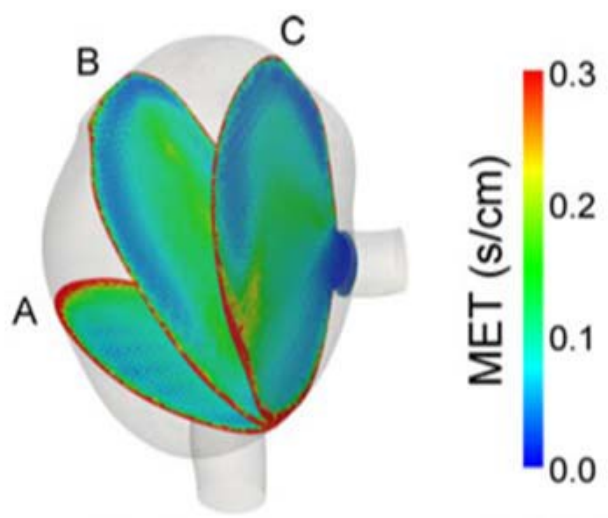

\section{No Stent}

A

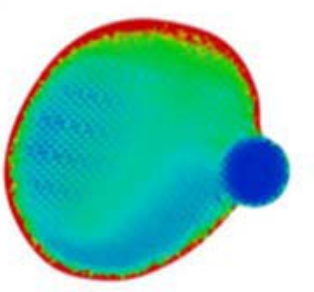

N2-12×16

\section{B}
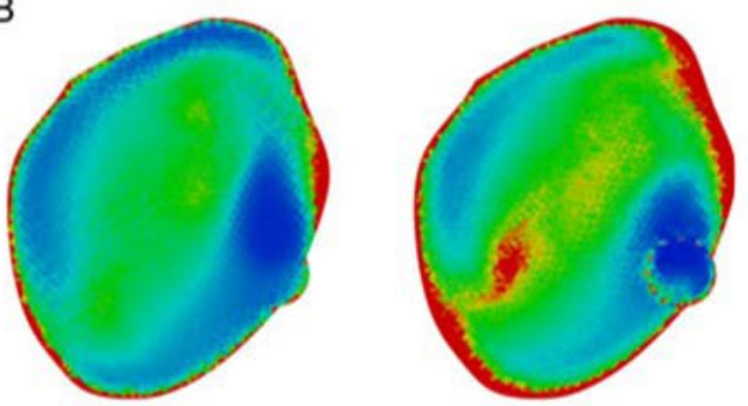

C
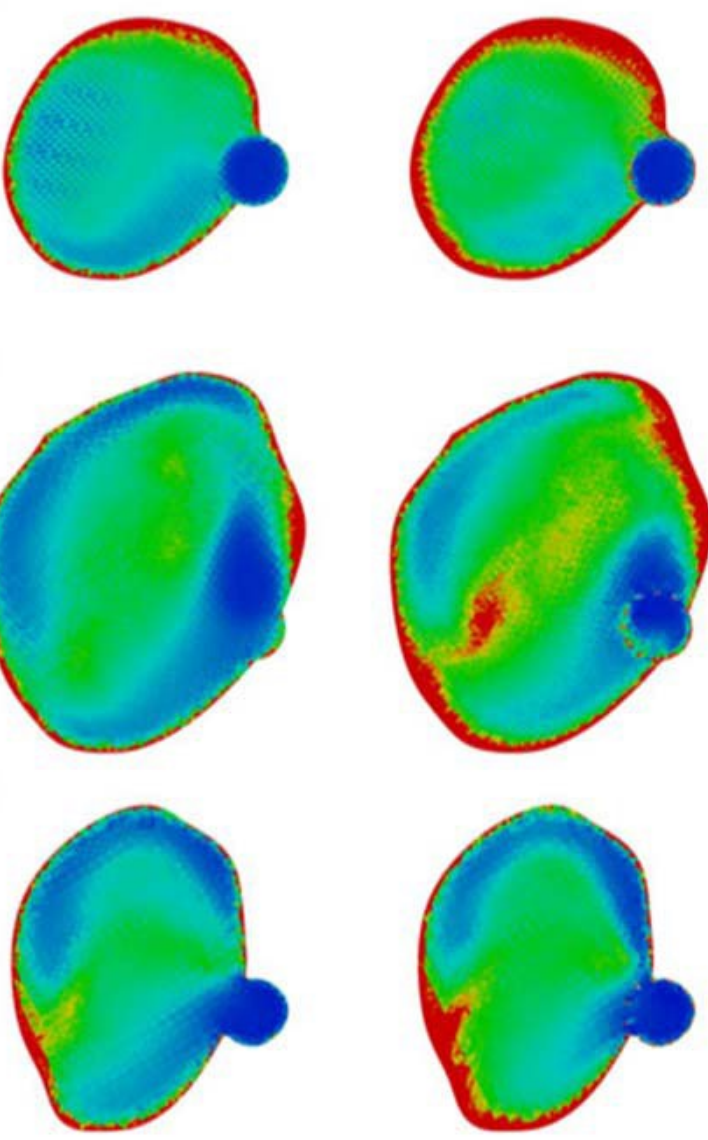

Cross-sections of the mean exposure time (MET) field at three locations within an unstented aneurysm and an aneurysm with the N2-12316 stent across the aneurismal neck.

Annals of Biomedical Engineering, Vol. 39, No. 5 (May 2011): pg. 1423-1437. DOI. This article is @ Springer and permission has been granted for this version to appear in e-Publications@Marquette. Springer does not grant permission for this article to be further copied/distributed or hosted elsewhere without the express permission from Springer. 
Figure 7
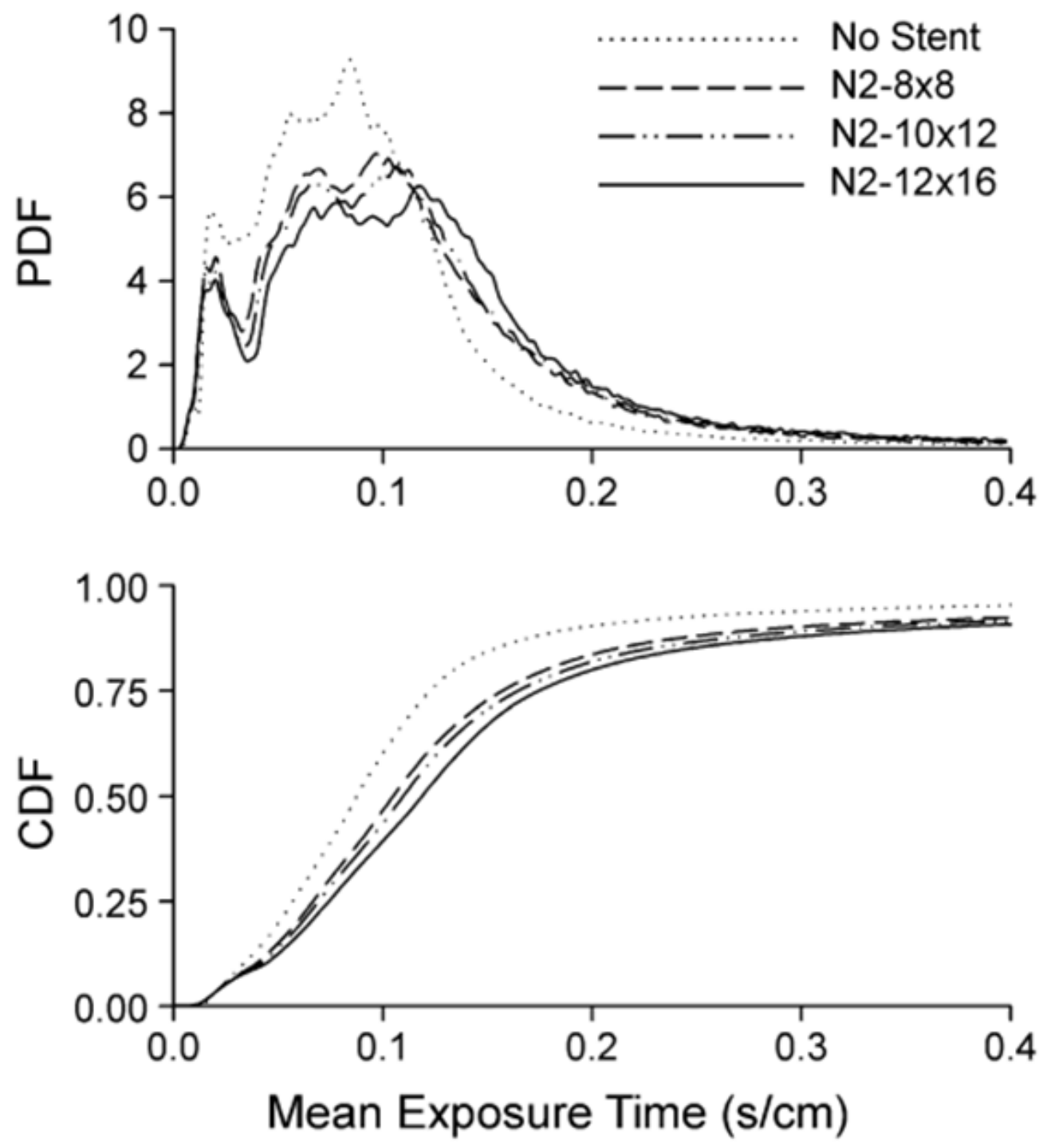

(Top) Probability density function and corresponding (Bottom) cumulative distribution function of the mean exposure time field within the aneurysm volume of four basilar trunk aneurysm models in which various stents were placed across the neck of the aneurysm. 